\title{
Knowledge of Supervision on Treatment About Prevention and Infection of Tuberculosis
}

\author{
Upik Rahmi* \\ Nursing Program Study \\ Universitas Pendidikan Indonesia \\ Bandung, Indonesia \\ *upikrahmi@upi.edu
}

\begin{abstract}
The World Health Organization (WHO) recommends treatment for tuberculosis with the Directly Observed Treatment Short course chemotherapy (DOTS) strategy, one of which is in the form of a health worker. It is very important to ensure that the patient has swallowed all the medicines given as directed by direct supervision by the health worker. The purpose of this research is to find out the health worker knowledge of swallowing drugs about the treatment and prevention of tuberculosis infection. Method This research uses descriptive quantitative research using frequency distribution. The research sample consisted of 43 respondents using accidental sampling with univariate analysis presented in the frequency distribution table. Results of this study of 43 respondents found as many as 38 people $(\mathbf{8 8 . 4 \%})$ have good knowledge, this is influenced by the level of education of respondents and the provision of health education routinely for tuberculosis sufferers and health worker. Conclusion, the health worker knowledge of swallowing drugs about the treatment and prevention of tuberculosis infection is good.
\end{abstract}

Keywords: health worker, knowledge, tuberculosis

\section{INTRODUCTION}

TB occurs in every part of the world. In 2018, the largest number of new TB cases occurred in the South-East Asia region, with $44 \%$ of new cases, followed by the African region, with $24 \%$ of new cases and the Western Pacific with $18 \%$. In $2018,87 \%$ of new TB cases occurred in the 30 high TB burden countries. Eight countries accounted for two thirds of the new TB cases: India, China, Indonesia, the Philippines, Pakistan, Nigeria, Bangladesh and South Africa [1].

In Indonesia, the incidence of TB cases is 842,000 per year and notification of TB cases is 569,899 cases, so there are still around $32 \%$ of the cases that have not been verified either unreached, undetected or not reported. From this incident rate the TB burden is calculated in each province and district / city [2]. Healthy behaviour is as, "every action taken by an individual to find treatment [3]. This is based on a model of a particular cultural picture that influences people's health behaviours. Which consists of signs and symptoms of the disease, the cause of the disease and the prognosis of the disease [4]. This is interpreted by individuals and / or other people related to health problems, to deal appropriately through recommended therapies [4].
TB treatment requires knowledge both from the sufferer and from the companion to take medicine [5]. Since 1993, WHO has published international TB treatment guidelines, which aim to provide a national TB program (NTP) and the medical profession with evidence-based practical guidance on effective TB case management [6].

\section{Materials AND MethoD}

\section{A. Materials}

Tuberculosis (TB) is caused by the bacteria (Mycobacterium tuberculosis) that most often attacks the lungs. TB can be cured and prevented. TB spreads from person to person through the air. When people with pulmonary TB cough, sneeze or spit, they push TB germs into the air. One needs to breathe in only a few of these germs to become infected. About a quarter of the world's population has latent $\mathrm{TB}$, which means people have been infected by TB bacteria but have not (yet) been sick with this disease and cannot transmit the disease.

\section{B. Participants and Study}

Design Across-sectional based survey study (quantitative and observational) was conducted employing selfadministered questionnaire at the Public of health, Indonesia. The participants were is health worker of drug therapy Tuberculosis male and female. The participants were informed in advance about the objective of the study. The research sample consisted of 43 respondents.

\section{Data Collection Methods}

A self-administered and bilingual questionnaire (Sundanis and bahasa) was developed. The population 187 participant TB patients. The questionnaire was piloted on 43 participants and modified as per the need and further validated. The survey questionnaire was divided in two sections. The first section involved the questions about the demographic details of the participants. While, the second section pertained to the questions covering the knowledge of volunteer about therapy and prevention of Tuberculosis. Statistical analysis is data collected were tabulated in MS Excel sheet, and ana- lyzed. 
especially in countries like Indonesia where the disease is still very much [9]. Nurses also influence patient knowledge and compliance by changing patient stigma about TB treatment [10]. In addition to knowledge about $\mathrm{TB}$ prevention and infection, health workers must also have knowledge about TB drugs [5].

Health worker is one of the TB treatment health workers, because health workers need to provide health education to improve the knowledge and attitudes of patients towards TB disease [11], because knowledge is the basis for any practice and for controlling TB. Clinical experience and health education affect one's level of knowledge [12].

Social closeness between health workers (companion taking drugs) and patients will increase knowledge and adherence to TB infection prevention behaviour [9]. This is because if the lack of knowledge about national and international TB guidelines and treatment will affect the treatment of TB patients [5]. He right behaviour of health workers will influence the treatment of TB patients [3] and patient satisfaction with TB services and care [13], this is also influenced by the closeness of patients with health workers, health workers for TB care compliance [9].

\section{CONCLUSIONS}

Most of the well-informed Health worker were influenced by the level of education of respondents who were mostly high school / equivalent and good health education by health workers, especially nurses who handled the TB program.

\section{REFERENCES}

[1] WHO _ Gender and tuberculosis. (n.d.).

[2] Indonesia, M. of H, TB Indonesia, 2019, retrieved from: https://www.tbindonesia.or.id/page/view/11/situasi-tbc-di-indonesia.

[3] O.O. Latunji, O.O. Akinyemi and F. Health, "Factors Influencing Health-Seeking Behaviour Among Civil Servants In Ibadan , Nigeria," vol. 16(1), 2018.

[4] J. Olenja, "Editorial: Health seeking behaviour in context," East African Medical Journal, vol. 80(2), pp. 61-62, 2003.

[5] M.J. Van Der Werf, M.W. Langendam, E. Huitric and D. Manissero, Series "rational use of anti-tuberculosis drugs" - Knowledge of tuberculosis-treatment prescription of health workers: A systematic review, European Respiratory Journal, vol. 39(5), pp. 1248-1255, 2012.

TABLE II. KNOWLEDGE OF SUPERVISION ON TREATMENT ABOUT PREVENTION AND INFECTION TUBERCULOSIS (TB)

\begin{tabular}{|l|l|l|}
\hline \multicolumn{1}{|c|}{ Knowledge } & \multicolumn{1}{c|}{$\mathbf{N = 4 3}$} & \multicolumn{1}{c|}{$(\%)$} \\
\hline Good & 38 & 88,4 \\
Enought & 3 & 7 \\
Less & 2 & 4,6 \\
\hline Total & 43 & 100 \\
\hline \multicolumn{2}{|c|}{ Source: primary data. }
\end{tabular}

\section{DISCUSSION}

Improving patient knowledge about $\mathrm{TB}$ is an important component and the main goal of TB treatment and companion knowledge of taking medication [7]. Health workers are often the main source of information about TB for patients [8]. Effective communication about the causes of TB, its symptoms, treatment, and how it is spread is very important,
[6] World Health Organisation, Tuberculosis WHO., 2019, retrieved from: https://www.who.int/news-room/fact-sheets/detail/tuberculosis.

[7] F. Rehman, R. MA, A.S. Rao, A. Hasan and Q. M, "Knowledge about Tuberculosis and its Complication among the Patients in a Teaching Hospital," Journal of Pulmonary \& Respiratory Medicine, vol. 07(01), pp. 1-4, 2017.

[8] A. Trajman, M.F. Wakoff-Pereira, J. Ramos-Silva, M. Cordeiro-Santos, M de F Militão de Albuquerque, P.C. Hill and D. Menzies, "Knowledge, attitudes and practices on tuberculosis transmission and prevention among auxiliary healthcare professionals in three Brazilian high-burden cities: a cross-sectional survey," BMC Health Services Research, vol. 19(1), pp. 1-8, 2019.

[9] M. Pai, C. Delavallade, S. Huddart, T. Bossuroy, V. Pons and S. Baral, "Knowledge about tuberculosis and infection prevention behavior: A nine city longitudinal study from India," PLoS ONE, vol. 13(10), pp. 115, 2018.

[10] B.S. Nkambule, J. Lee-Hsieh, C.Y. Liu and S.F. Cheng, "The relationship between patients' perception of nurse caring behaviors and 
[12] N. Yükseltürk and L. Dinç, "Knowledge about anti-tuberculosis treatment among nurses at tuberculosis clinics," International Journal of Nursing Practice, vol. 19(1), pp. 47-53, 2013.

[13] S.M. Ali, N. Anjum, F. Naureen, A. Rashid and A. Tahir, "Satisfaction Level of Tuberculosis Patients Regarding Their Access to TB Care and Prevention Services, Delivered Through a Public - Private Mix Model in Pakistan," pp. 1-10, 2019. and H.C.J.D.Van Rensburg, "Tuberculosis knowledge, attitudes and
practices of patients at primary health care facilities in a South African metropolitan: Research towards improved health education," BMC Public Health, vol. 17(1), pp. 1-8, 2017.

tuberculosis stigma among patients with drug-resistant tuberculosis in Swaziland," International Journal of Africa Nursing Sciences, pp. 1418, 2019. https://doi.org/10.1016/j.ijans.2018.11.004

[11] N.G. Kigozi, J.C. Heunis, M.C. Engelbrecht, A.P. Janse Van Rensburg 